\title{
$\angle S$ Research Soure \\ The effects of ethyl lauroyl arginine hydrochloride (ELAH) in nasal spray formula on SARS-Cov-2
}

Harshad R. Thacore

SUNY at Baffalo

Abdul Gaffar ( $\sim$ agaffar@verizon.net )

Salvacion inc

Seiyoung Yun

Daejeon Health Institute of Technology

Agnes L. Chenine

IBT Bioservices

Maria . G. Ferrari

Bioqual

\section{Research Article}

Keywords: SARS-CoV-2, ethyl alauroyl arginine hydrochloride, prevention

Posted Date: September 21st, 2021

DOI: https://doi.org/10.21203/rs.3.rs-842564/v1

License: (c) (1) This work is licensed under a Creative Commons Attribution 4.0 International License.

Read Full License 


\section{Abstract}

SARS-CoV-2 and coronaviruses, enveloped RNA viruses, are major causes of acute human respiratory diseases. The aim of the study was to investigate the broad-spectrum antiviral effects of ethyl lauroyl arginine hydrochloride (ELAH) in in vitro and in vivo assays. Cell-based assays found that the pseudovirus VSV-SARS-CoV-2 was inhibited with an $\mathrm{EC}_{50}$ of 15 micrograms/ml, with complete inhibition achieved at 110 micrograms $/ \mathrm{ml}$. The effects were comparable to those observed with anti-SARS-CoV-2 antibody neutralization assays against VSV-SARS-CoV-2. Intranasal administration of the Wuhan strain of SARS-CoV-2 treated in vitro with ELAH inhibited the disease symptoms caused by the virus in a Syrian hamster model compared to that caused by the same dose of virus treated in vitro with medium alone. Subgenomic RNA and total RNA viral load were concomitantly reduced in the treated animals compared with the control group. In cell-based studies, pretreatment of susceptible cells with 1-10 micrograms/ml ELAH inhibited the attachment of the virus to the cells, as measured by cytopathic and high-resolution scanning electron microscopy (SEM) effects, suggesting that the primary mode of ELAH action was due to preventing the attachment of the virus to the cells. Collectively, the data suggest that ELAH could be a promising agent for the prevention of SARS infection through nasopharyngeal surfaces.

\section{Introduction}

In December 2019, a novel coronavirus (SARS-CoV-2) emerged in Wuhan, China, and in a matter of months, the virus rapidly spread throughout the world (Koopmans M. 2020). The World Health Organization (WHO) declared the outbreak a pandemic in March 2020 (Koopmans M. 2020). This highly contagious respiratory disease, coronavirus disease 2019 (COVID-19), caused by SARS-CoV-2 virus enters the host via the respiratory route and infects the lungs and other organs of the body (Gandhi RT, and others, 2020). Since the port of entry of the virus is via the nasopharynx, we present data with regard to the efficacy of our nasal spray product in preventing the virus from causing a severe disease.

The compound N-alpha-lauroyl-L-arginine ethyl ester monohydrochloride (LEAH or ELAH - FDA designation) is a derivative of lauric acid, arginine and ethanol. The main characteristic of this molecule is that it prevents the proliferation and colonization of microbial films in oral and nasal mucosal surfaces (Gallob, JT et al, 2015). ELAH is hydrolyzed in the human body by chemical and metabolic pathways, which break the molecule into natural compounds in the human diet (Hawkins, D.R., 2009t). The FDA has approved ELAH and classified it as a GRASE, generally recognized as safe and effective for use in meats and poultry as a food preservative (FDA 2005 GRAS notice. GRN 000164, no objection letter from FDA Sept 2005: The EFSA journal (20027)511;1-27).

The antiviral and virucidal activity of arginine surfactants, such as L-Cocoyl-L- arginine ethyl ester, against herpes simples, influenza $A$ and polioviruses has been extensively studied by Hasashi Yamasaki et al. (Yamasaki, $\mathrm{H}$ et al, 2011). However, they did not study the lauric acid ester of arginine in their studies. 
In this report, we present the results of in vitro and in vivo studies on SARS-CoV-2 virus. The effect of ELAH applied through a specific formulation for nasal delivery to arrest, block or prevent the colonization of the virus in the nasopharyngeal area and indicate that ELAH, due to its excellent safety profile, could be a useful agent for augmenting preventative measures for SARS-CoV-2 on mucosal and nasopharynx surfaces.

\section{Experimental Section}

Recombinant VSV: rVSV-dG SARS-CoV-2 S: The recombinant vesicular stomatitis virus (rVSV) whose glycoprotein gene $(\mathrm{G})$ has been deleted is used as the base platform for IBT Bioservices's pseudo typebased neutralization assay (Whitt 2010). The VSV-G glycoprotein is transiently expressed by transfection to produce virus particles. To create a pseudotype virus, VSV-G is substituted with the SARS-CoV2 spike protein lacking the last eighteen amino acids of the cytoplasmic domain. The resulting virus, rVSV- $\triangle$ G SARS-CoV-2 S, also expresses firefly luciferase and can be handled at biosafety level 2 (BSL-2). Infection efficiency was measured by quantification of luciferase activity reading the relative light units (RLU). Briefly, rVSV- $\triangle$ G SARS-CoV-2 S was preincubated with and without ELAH along with SARS-CoV-2 seropositive rat sample (IBT Bioservices)used as internal assay control. Rats serum was obtained after immunizing rats in house with SAR-CoV-2 spike protein and added to Vero cells .. After 24hours infection, firefly luciferase activity wasmeasured and the $50 \%$ inhibitory dose $\left(\mathrm{ID}_{50}\right)$ defined as the reciprocal of the serologic reagent dilution that caused a $50 \%$ reduction in RLUs compared to virus control wells was determined.

Formula for nasal spray: The formula contains $0.1 \%$ ELAH, glycerin, xylitol (moisturizing agents), 1,2hexanediol, polyvinyl pyrrolidone, PEG-40 hydrogenated castor oil, phenoxyethanol and cupric gluconate as preservatives, citric acid for buffer and deionized distilled water (COVIXYL-V).

Neutralization Assay: Vero cells were seeded at 60,000 cells/well in 96-well flat bottom black cell culture plates in Dulbecco's modified Eagle medium (DMEM) containing 10\% serum and incubated overnight. Four dilutions of ELAH were prepared in $1 \%$ serum medium at two times $(2 \mathrm{X})$ the final intended concentration.

Virus dilution and ELAH/virus mix preincubation: rVSV-SARS-CoV-2 $S$ was diluted 1:10 in $1 \%$ serum medium to obtain a final dilution of $1: 20$ in $2.5 \mathrm{ml}$ and $175 \mu \mathrm{l}$ of virus inoculum was then mixed to 175 $\mu \mathrm{l}$ of each ELAH concentrations for $350 \mu \mathrm{l}$ final; $350 \mu \mathrm{l}$ of virus only was also prepared. All mixtures were incubated for 1 hour at $37^{\circ} \mathrm{C}$ and $5 \% \mathrm{CO} 2$. All the medium was removed from the 96 -well black plates, and $100 \mu \mathrm{l}$ of each virus/TA (testing article) mixture was added in triplicate to the Vero cells. One hundred microliters of virus only and $100 \mu \mathrm{l}$ of $1 \%$ serum medium were also added to a minimum of 6 wells and incubated for 24 hours at $37^{\circ} \mathrm{C}$ and $5 \% \mathrm{CO} 2$.

Firefly luciferase readout: $100 \mu \mathrm{l}$ of Bright-Glo reagent was added to each well as instructed by the manufacturer. Plates were read immediately in our luminometer, and the relative light unit (RLU) was 
measured.

Animal Model Studies: The Syrian golden hamster was chosen as the animal model for this study based on in-house data and recent publications indicating that SARS-CoV-2 productively replicates in this model and that aspects of COVID-19 are recapitulated (Tostanoski, L, H,2020 and others). A total of 21 male and female Golden Syrian hamsters (6-8 weeks old, approximately $100 \mathrm{~g}$ of weight) were purchased from Envigo (Indianapolis, IN, barrier 202C). The animals were received in good condition. Animal acclimation and husbandry followed the procedures and practices outlined in the IACUC Study Protocol.

The animal study was conducted in BIOQUAL's animal facility, BIOQUAL's facilities are OLAW assured (A3086-01), USDA registered (51R 036), and have Full AAALAC Accreditation (File no. 624). Additionally, BIOQUAL has CDC/USDA approval for working with restricted BSL-2 and BSL-3 Select Agents and has approved ABSL/BSL-3 facilities and training for working with infectious agents under containment. Housing and handling of the animals were performed in accordance with the animal welfare requirements and accreditations stated above. Based on the final study plan, BIOQUAL prepared, submitted, and received approval for the IACUC protocol. BIOQUAL Study Directors of both Animal/Veterinary Services and Laboratory Services reviewed the IACUC protocol submission to ensure that all scheduled procedures were consistent with the approved final study plan. This nonclinical study was performed under the BIOQUAL Institutional Animal Care and Use Committee approved Protocol (IACUC Protocol Number: 20-153P) and was conducted in accordance with the Study Protocol and BIOQUAL Standard Operating Procedures (SOPS).

Experimental design and grouping: A study design was prepared in collaboration with BIOQUAL and Merck research scientists and finalized in a study protocol prior to the start of the study. In Study 1 , retention of ELAH after a single administration followed by mock challenge was examined over time, while in Study 2, hamsters challenged with virus treated in vitro either with medium or with ELAH were evaluated for infection and clinical outcome.

Study 1 was conducted with a total of six animals divided equally into three groups. ELAH ( $50 \mu \mathrm{l}$ per nare) was administered into each nare of the animals. Each animal then received $50 \mu$ of DMEM containing 2\% FBS per nostril after $10 \mathrm{~min}$ for Group 1, $15 \mathrm{~min}$ for Group 2 and 20 min for Group 3 to mimic mock infection. Leakage of solution was monitored for 10 min after each mock infection.

For Study 2, a total of 15 animals divided equally into three groups were used. Group 1 animals were challenged with virus treated in vitro with undiluted ELAH; Group 2 animals were challenged with virus treated in vitro with diluted ELAH (dose diluted 1:1 in sterile PBS), and Group 3 animals were challenged with virus treated in vitro with medium alone. Each treatment was performed at $37^{\circ} \mathrm{C}$ in $5 \% \mathrm{CO} 2$ for 10 min. Daily weights and BID observations during challenge periods SD 1, 2, 3, 4, 5, 6, 7, 10 and 14 .

Preparation and Administration Procedures: For Study 1, ELAH-COVIXYL-V solution was applied directly followed by DMEM containing $2 \%$ FBS. For Study 2, a vial of SARS-CoV-2 virus was thawed, and the virus was divided into groups: 
Group 1: Virus stock $(0.2 \mathrm{ml})$ was diluted to $1.8 \mathrm{ml}$ with medium by adding $1.6 \mathrm{ml}$ of medium and $0.2 \mathrm{ml}$ of ELAH-COVIXYL-V and incubated at $37^{\circ} \mathrm{C}$ in a $5 \% \mathrm{CO} 2$ incubator for $10 \mathrm{~min}$. Each animal was challenged nasally with $0.1 \mathrm{ml}$ of virus $(0.05 \mathrm{ml}$ per nare).

Group 2: ELAH-COVIXYL-V $(0.5 \mathrm{ml})$ was diluted to $1 \mathrm{ml}$ with $0.5 \mathrm{ml}$ of sterile PBS. Virus stock (0.2 $\mathrm{ml})$ was diluted to $1.8 \mathrm{ml}$ with medium by adding $1.6 \mathrm{ml}$ of medium and $0.2 \mathrm{ml}$ of diluted ELAH-COVIXYL-V (1:1) and incubated at $37^{\circ} \mathrm{C}$ in a $5 \% \mathrm{CO} 2$ incubator for $10 \mathrm{~min}$. Each animal was challenged nasally with $0.1 \mathrm{ml}$ of virus (0.05 $\mathrm{ml}$ per nare).

Group 3 (Control): Virus stock $(0.2 \mathrm{ml})$ was diluted to $2 \mathrm{ml}$ by adding $1.8 \mathrm{ml}$ of medium and incubated at $37^{\circ} \mathrm{C}$ in a $5 \% \mathrm{CO} 2$ incubator for $10 \mathrm{~min}$. Each animal was challenged nasally with $0.1 \mathrm{ml}$ of virus $(0.05 \mathrm{ml}$ per nare).

Challenge of hamsters with SARS-CoV-2: ELAH- or medium-treated SARS-CoV-2 was administered intranasally (IN) to anesthetized hamsters and performed in a BSL-3 laboratory. The administration of virus was conducted as follows: Using a calibrated pipettor, $0.05 \mathrm{~mL}$ of the viral inoculum was administered dropwise into each nostril, $0.1 \mathrm{ml}$ per animal while the animal's head was tilted back so that the nostrils were pointing toward the ceiling. syringe into the first nostril and slowly the inoculum into the nasal passage, and then removed. This was repeated for the second nostril. The animal's head was tilted back for approximately 20 seconds and then returned to its housing unit and monitored until fully recovered. Body weights were measured once daily during the challenge phase. The animals were monitored twice daily during the morning and afternoon for signs of COVID-19 disease (ruffled fur, hunched posture, labored breathing) during the study period, starting on the day of SARS-CoV-2 challenge, and the information was recorded on BIOQUAL clinical observation forms and/or the Pristima ${ }^{\circledR}$ database. The raw data for the body weights and the clinical observations were made and recorded.

Specimen collection: Only oral swabs were collected on study days 1, 2, 3, 4, 5, 6, 7, 10 and 14 post challenge as per the study protocol. Scheduled euthanasia and necropsies were carried out for each nare.

Specimen Processing for viral RNA and viral subgenomic RNA assays: For viral load assays of oral swabs, the samples were processed. Upon collection, the swabs were placed into $1 \mathrm{ml}$ of PBS and then snap-frozen. Samples were then thawed, and an aliquot of the sample was used for RNA isolation following the manufacturer's instructions (Qiagen, Cat. No. 57704).

Viral RNA quantitation: The qRT-PCR assay was used for quantitation of viral RNA from the oral swabs using the primers and a probe specifically designed to amplify and bind to a conserved region of Nucleocapsid gene of Coronavirus (Forward primer: 5'-GAC CCC AAA ATC AGC GAA AT-3'; Reverse Primer: 5'-TCT GGT TAC TGC CAG TTG AAT CTG-3' and Probe: 5'-FAM-ACC CCG CAT TAC GTT TGG TGG ACCBHQ1-3') as described elsewhere (Baum et al. REGN-COV2 antibodies prevent and treat SARS-CoV-2 infection in rhesus macaques and hamsters. science.sciencemag.org/cgi/content/full/science. abe2402/DC1). The signal was compared to a known standard curve and calculated to give copies per 
$\mathrm{mL}$. For the qRT-PCR assay, viral RNA was first isolated from oral swabs using the Qiagen Min Elute virus spin kit (cat. no. 57704). To generate a control for the amplification reaction, RNA was isolated from the applicable COVID virus stock using the same procedure. The amount of RNA was determined from an O.D. reading at 260 , using the estimate that $1.0 \mathrm{OD}$ at $\mathrm{A} 260$ equals $40 \mu \mathrm{g} / \mathrm{mL}$ of RNA. With the number of bases known and the average base of RNA weighing $340.5 \mathrm{~g} / \mathrm{mole}$, the number of copies was then calculated, and the control was diluted accordingly. A final dilution of $10^{8}$ copies per $3 \mu \mathrm{L}$ was then divided into single use aliquots of $10 \mu \mathrm{L}$ and stored at $-80^{\circ} \mathrm{C}$. For the master mix preparation, $2.5 \mathrm{~mL}$ of $2 X$ buffer containing Taq-polymerase, obtained from the TaqMan RT-PCR kit (Bioline cat\# BIO-78005), was added to a $15 \mathrm{~mL}$ tube. From the kit, $50 \mu \mathrm{L}$ of RT and $100 \mu \mathrm{L}$ of RNAse inhibitor were also added. The primer pair at a $2 \mu \mathrm{M}$ concentration was then added in a volume of $1.5 \mathrm{~mL}$. Finally, $0.5 \mathrm{~mL}$ of water and $350 \mu \mathrm{L}$ of the probe at a concentration of $2 \mu \mathrm{M}$ were added, and the tube was vortexed. For the reactions, $45 \mu \mathrm{L}$ of the master mix and $5 \mu \mathrm{L}$ of the sample RNA were added to the wells of a 96-well plate. All samples are tested in triplicate. The plates were sealed with a plastic sheet. For control curve preparation, samples of the control RNA were prepared to contain $10^{6}$ to $10^{7}$ copies per $3 \mu \mathrm{L}$. Eight (8) $10-$ fold serial dilutions of control RNA were prepared using RNAse-free water by adding $5 \mu \mathrm{L}$ of the control to $45 \mu \mathrm{L}$ of water and repeating this for 7 dilutions. This generated a standard curve with a range of 1 to $10^{7}$ copies/reaction. For amplification, the plate was placed in an Applied Biosystems 7500 Sequence detector and amplified using the following program: $48^{\circ} \mathrm{C}$ for 30 minutes, $95^{\circ} \mathrm{C}$ for 10 minutes followed by 40 cycles of $95^{\circ} \mathrm{C}$ for 15 seconds, and 1 minute at $55^{\circ} \mathrm{C}$. The number of copies of RNA per $\mathrm{mL}$ was calculated by extrapolation from the standard curve and multiplying by the reciprocal of $0.2 \mathrm{~mL}$ extraction volume.

Subgenomic RNA quantitation: The method used for quantitation of subgenomic mRNA measured by an RT-qPCR assay was similar to what was described elsewhere (Wölfel R., Corman V.M., and others (2020)).

The primers and probe selected from the $\mathrm{N}$ gene (Forward:

5'-CGATCTCTTGTAGATCTGTTCTC-3'; reverse: SG-N-R: 5'-GGTGAACCAAGACGCAGTAT-3' and probe: 5'FAM- TAACCAGAATGGAGAACGCAGTGGG -BHQ-3') were similar to what was previously described (Li et al. 2021). The PCR signal obtained with the sample was compared to a known standard curve of plasmid containing the sequence of part of the messenger RNA and calculated to give copies per $\mathrm{ml}$. To generate a control for the amplification reaction, a plasmid containing a portion of the $\mathrm{N}$ gene messenger RNA was used. A final dilution of 106 copies per $3 \mu \mathrm{l}$ was then divided into single use aliquots of $10 \mu \mathrm{l}$ and stored at $-80^{\circ} \mathrm{C}$ until needed. The samples extracted for viral RNA were then amplified in duplicate to pick up sgRNA. Seven (7) 10 -fold serial dilutions of control RNA were prepared by adding $5 \mu$ l of the control to 45 $\mu \mathrm{l}$ of water and repeating this for 7 dilutions, leading to the generation of a standard curve with a range of 1 to $10^{6}$ copies/reaction. For amplification, the plate was placed in an Applied Biosystems 7500 Sequence detector and amplified using the following program: $48^{\circ} \mathrm{C}$ for 30 minutes, $95^{\circ} \mathrm{C}$ for 10 minutes followed by 40 cycles of $95^{\circ} \mathrm{C}$ for 15 seconds, and 1 minute at $55^{\circ} \mathrm{C}$. A printout of the results is 
maintained in the laboratory notebook. The number of copies of RNA per ml was calculated by extrapolation from the standard curve and multiplying $0.2 \mathrm{~mL}$ of extracted volume.

The effect of pretreatment of MRC-5 cells with ELAH on the replication of human coronavirus 229E: A human lung fibroblast MRC-5 (ATCC $®$ CCL-171 ${ }^{\mathrm{TM}}$ ) cell line grown in Eagle's Minimum Essential Medium (EMEM) containing $2 \%$ fetal bovine serum and human coronavirus $229 \mathrm{E}$ (ATCC $\AA$ VR-740 ${ }^{\mathrm{TM}}$ ) was used in these experiments.

Preliminary experiments were conducted to determine the cytotoxicity of ELAH on MRC- 5 cell cultures. Serial 10 -fold dilutions of ELAH starting with a stock solution containing $0.08 \%$ or $800 \mu \mathrm{g} / \mathrm{ml}$ ELAH or cell medium only as a control were added to MRC- 5 cell cultures and incubated for 6 days. Cytotoxicity screening using bright field imaging was conducted to determine the lowest noncytotoxic concentration of ELAH in MRC-5 cell cultures under these experimental conditions.

To assess the replication of human coronavirus 229E in MRC- 5 cells pretreated with ELAH, the following experiment was conducted. Noncytotoxic concentrations of ELAH were added to MRC-5 cell cultures at $37^{\circ} \mathrm{C}$ for 10 minutes. The culture medium containing unbound ELAH was removed from treated cell cultures, and human coronavirus $229 \mathrm{E}$ was added to the cells and incubated at $35^{\circ} \mathrm{C}$ for an additional $2 \mathrm{~h}$ for the virus to adsorb to the cells. The virus inoculum was removed, and the cultures were washed with medium and reincubated for 4 days at $35^{\circ} \mathrm{C}$. Appropriate controls, medium alone, were also included in the experiment. Virus yield from cultures pretreated with ELAH and control nontreated cells was assayed for virus yield by $\operatorname{TCID}_{50}$, and virus-induced cytopathic effect (CPE) was determined by bright field imaging using an Olympus BX63 microscope and Olympus cellsSens Dimension software of the ELAHtreated and control MRC-5 cell cultures.

Inhibition of cytopathic effect by human coronavirus 229E in MRC- 5 cells pretreated with ELAH as assessed by bright field microscopy: MRC- 5 cells were seeded at $1 \times 105$ cells $/ \mathrm{ml}$ in 4 -chamber cell culture slides and incubated at $37^{\circ} \mathrm{C}$ for 4 days until approximately $85-90 \%$ confluency was obtained. Two concentrations of ELAH, $1 \mu \mathrm{g} / \mathrm{ml}$ and $10 \mu \mathrm{g} / \mathrm{ml}$, in DMEM were added to the cells and incubated for 10 minutes at $37^{\circ} \mathrm{C}$. Cell cultures treated with medium only were used as controls. ELAH was then removed from the cell cultures and infected with a $10^{\wedge} 3$ dilution of stock human coronavirus $229 \mathrm{E}$ $\left(\log _{10} \mathrm{TCID}_{50} / \mathrm{ml} 5.625\right)$, and cultures were reincubated at $35^{\circ} \mathrm{C}$ for 2 hours. Similarly, cells not treated with ELAH were also infected with 229E. After a 2-hour adsorption period, the unadsorbed virus was removed, and the cells were washed, refed with medium and incubated for 48 hours at $35^{\circ} \mathrm{C}$. Control cultures were treated in a similar manner. After 48 hours, chamber cell cultures were imaged via bright field microscopy at a magnification of X63. Samples for scanning electron microscopy were fixed with $1 \mathrm{ml}$ glutaraldehyde for 2 hours and processed according to Caldas et al. (2020). SEM imaging was conducted at the University of Wyoming's Materials Characterization Laboratory. After samples underwent fixation, they were placed in a Kinney Vacuum KSE-2A-M Evaporator under 10^-4 Torr vacuum for 24 hours and then sputtered with a $5 \mathrm{~nm}$ thick gold coat using a Model 30000 Ladd Research Industries apparatus.

Secondary electron and backscattered electron images were collected on a Quanta 250 scanning electron 
microscope under $10^{\wedge}-5$ Torr vacuum using an accelerating voltage of $5 \mathrm{kV}$ and spot sizes of 2 and 3 . Electronic alignments on the electron gun (Gun Alignment, Final Lens Aperture Alignment, and Stigmator Alignment) were performed prior to imaging to optimize resolution.

\section{Results}

Effect of ELAH on the replication of rVSV-dG SARS-Covid-2S in Vero cells: A recombinant vesicular stomatitis virus (VSV) was used in which the glycoprotein gene (G) was deleted and substituted with fulllength SARS-Covid-19 spike protein and a firefly luciferase as described in the Materials and Methods. This construct was able to infect, replicate and cause cytopathic effects in Vero cells as well as express firefly luciferase. The infection efficacy in Vero cells was measured by quantification of the luciferase activity reading the relative light units (RLU) on a luminometer. This construct was used to study the interaction of ELAH and the spike protein of SARS-Covid-19.

Briefly, rVSV-dG SARS-Covid-2S was incubated with and without ELAH as well as with 2019 SARS-Covid-2 neutralizing antibody serum as a control for $1 \mathrm{hr}$ at $37^{\circ} \mathrm{C}$. Vero cells grown in 96-well flat bottom cell culture plates were infected in triplicate with virus incubated with or without $\mathrm{ELAH}$ as well as antiserumtreated virus and incubated for $24 \mathrm{hrs}$ at $37^{\circ} \mathrm{C}$. A minimum of six Vero cell cultures were infected with virus only, and six wells of uninfected cell cultures were used as controls. Firefly luciferase activity was then measured in all wells, and inactivation and neutralization titers were calculated by the RLU values. Neutralization titers (50\% inhibitory dose, ID50) were defined as the reciprocal of the dilution that caused a $50 \%$ reduction in RLUs compared to virus control wells. The neutralization of rVSV-SARS-CoV-2 S by the 2019 anti-SARS-CoV-2 antiserum is presented in Figure 1. The results show that the antibodies bind to the spike protein in the construct and prevent its binding to Vero cell receptors, thus inhibiting replication. The results presented in Figure 2 show the inhibitory effect of ELAH on the replication of rVSV-SARS-CoV-2 S. Maximum inhibition of the replication of the virus, over $90 \%$, was obtained at a concentration of 110 $\mu \mathrm{g} / \mathrm{ml}$ ELAH (Figure 2). These results suggest that ELAH either binds to or alters the spike protein of the rVSV-SARS-CoV-2 S construct, thus preventing attachment to the receptor, entry and replication in Vero cells.

Efficacy of ELAH as a nasal spray in preventing severe disease in Syrian Golden hamsters: Studies have shown that Syrian Golden hamsters are a useful animal model for studying the pathogenesis of SARSCoV-2 (ref). SARS-COV-2 is a respiratory virus, and the nasal cavity is the main route of infection. A nasal spray is a possible route for the delivery of therapeutics as a preventive measure (ref). The following experiments were conducted in Syrian Golden hamsters to evaluate the efficacy of ELAH as a nasal spray in preventing clinical symptoms of SARS-CoV-2 infection.

Retention of nasally administered ELAH in Syrian Golden hamsters (Study 1): Preliminary experiments were conducted to determine the retention of ELAH when administered nasally without side effects. As described in the Materials and Methods, $50 \mu$ of ELAH was administered to each nare of a group of hamsters, and after 10,15 and 20 minutes, $50 \mu$ l of medium containing $2 \%$ fetal bovine serum was 
administered to each nare of hamsters to mimic mock infection. No leakage of either ELAH medium was observed in experimental animals 10 minutes after mock infection. While some moisture around the nose is normal for this procedure, the amount of moisture could not be quantified.

\section{Pretreatment of SARS-CoV-2 with ELAH inhibited the ability of the virus to synthesize viral sgRNA and viral RNA and induce clinical symptoms in hamsters. It has been well documented} that upon infection of hamsters with SARS-CoV-2 via the nasal route, one of the clinical symptoms observed is severe weight loss during the first few days of infection followed by recovery to normal weight (Tostanoski, $L, H, 2020$ ). Weight loss has been associated with the presence of virus in the respiratory tract (Tostanoski, LH,2020).

As described in the Materials and Methods, the animals were divided into groups. A constant amount of SARS-CoV-2 was incubated with two different concentrations of ELAH for 10 minutes at $37^{\circ} \mathrm{C}$. As controls, the virus was incubated with medium under similar experimental conditions. Each of the groups of animals was challenged with $0.1 \mathrm{ml}$ of treated or control mixtures $(0.05 \mathrm{ml} / \mathrm{nare})$. The body weights of each hamster were measured once daily, and the animals were also monitored twice daily for signs of COVID-19 disease as described in the Materials and Methods. The body weight changes observed in all animals during the course of 14 days are shown in Figure 3A. The results show that the animals infected with SARS-CoV-2 alone had a significant loss of weight during the first six days after challenge. These animals regained their original weight during the next eight days, as has been reported elsewhere (Tostanoski, L H,2020). In contrast, viruses treated with ELAH showed no significant weight loss during the 14-day course of the study. Similar results were also obtained with all females (Figure 3B) and male animals (Figure $3 \mathrm{C}$ ). These results indicate that the treatment of SARS-CoV-2 with ELAH under these experimental conditions significantly inhibits the ability of the virus to induce weight loss, a major indicator of clinical disease.

All three groups of animals were also tested for the number copies of subgenomic RNA (sgRNA) and region of the E gene messenger RNA from the coronavirus. The swabs were taken on days 1, 2, 3, 4, and 7 as described in the Materials and Methods. The results presented in Figure 4 show that in control group 3 , all animals demonstrated significant copies of sgRNA except for both animals on day 4 . In contrast, virus treated with undiluted ELAH (Group 1) prior to infection showed no detectable ( $<50$ copies) copies of sgRNA, except for one animal on day 1. In group 2, animals treated with 1:1 diluted ELAH, 4 out of 5 animals on day 4 were positive for the sgRNA, whereas three animals out four showed no detectable sgRNA on day 7. These results suggest that animals treated with ELAH significantly inhibit the synthesis of viral sgRNA synthesis, thus inhibiting the synthesis of progeny virions in ELAH-treated animals.

The presence of viral load in the three groups of animals as determined by the number of VRNA copies/swab is shown in Figure 5. In control group 3, all animals except for one animal had an average of 9.4 copies of viral RNA/swab. In contrast, in the animals infected with a mixture of virus and a high concentration of ELAH for 10 minutes at $37^{\circ} \mathrm{C}$ prior to infection, 4 animals had nondetectable viral RNA copies/swabs, and 4 animals had fewer viral RNA copies/swabs than the average found in control 
animals. In group 2 animals treated with half the concentration of ELAH compared to group 1, no detectable viral load was found in 3 animals, and 2 animals had viral load below the average in the control animals. Four animals in this group had viral loads higher than the average. These results suggest that pretreatment of SARS-CoV-2 with ELAH prior to infection of these animals significantly reduced not only the presence of viral sgRNA but also the viral load.

The effect of pretreatment of MRC-5 cells with ELAH on the replication of human coronavirus 229E. MRC5 cell cultures were pretreated with noncytotoxic concentrations of ELAH $(0.8$ and $0.08 \mu \mathrm{g} / \mathrm{ml})$ or with medium alone (control) for 10 minutes and infected with coronavirus 229E as described in the Materials and Methods. The results presented in Table 1 show a 0.25 and $0.5 \log 10 \mathrm{TCID} 50 / \mathrm{ml}$ drop in virus yield in cultures treated with 0.8 and $0.08 \mu \mathrm{g} / \mathrm{ml}$ ELAH, respectively, compared to the untreated control cultures. These results suggest that pretreatment of MRC- 5 cells with nontoxic concentrations of ELAH for 10 minutes reduced virus replication and a lack of cytopathic effects.

\section{TABLE:1}

\begin{tabular}{cccc}
\hline Test item & $\begin{array}{c}\text { Concentration } \\
\text { of active } \\
\text { (dilution) }\end{array}$ & $\begin{array}{c}\text { Recovery } \\
\left(\log _{10} \mathrm{TCID}_{50} / \mathrm{ml}\right)\end{array}$ & $\begin{array}{c}\text { Reduction } \\
\left(\mathrm{Log}_{10} \mathrm{TCID}_{50} / \mathrm{ml}\right)\end{array}$ \\
\hline $\begin{array}{c}\text { Negative (virus) } \\
\text { control }\end{array}$ & $\mathrm{N} / \mathrm{A}$ & 5.625 & $\mathrm{~N} / \mathrm{A}$ \\
\hline ELAH & $0.8 \mathrm{ug} / \mathrm{mL}$ & 5.375 & 0.25 \\
& $0.08 \mathrm{ug} / \mathrm{mL}$ & 5.125 & 0.50 \\
\hline
\end{tabular}

\section{Table 1. The effect of pretreatment of MRC-5 cells by ELAH on the} replication of human coronavirus 229E: Log recovery and reduction results for human coronavirus 229E following 10-minute pretreatment of MRC-5 cells (ATCC ${ }^{\circledR}$ CCL-171 ${ }^{\mathrm{TM}}$ ) with ELAH at two concentrations followed by 2hour incubation with virus compared to the negative control. Following incubation, the cell media was aspirated to remove unbound virus, and the cells were rinsed and incubated at $35^{\circ} \mathrm{C}$ for 4 days with culture media. $\mathrm{N} / \mathrm{A}=$ Not Applicable. Viral titer determined by TCID 50 .

\section{Inhibition of cytopathic effect (CPE) by human coronavirus 229E in MRC-5 cells pretreated with} ELAH. Briefly, MRC-5 cells grown in chamber cell culture slides were pretreated for 10 minutes with two concentrations $(1 \mu \mathrm{g} / \mathrm{ml}$ and $10 \mu \mathrm{g} / \mathrm{ml})$ of ELAH and infected for 2 hours with human coronavirus 229E as described in the Materials and Methods. Appropriate controls were also included. The cells treated with medium only (cell control) Figure 6A. or with $10 \mu \mathrm{g} / \mathrm{ml}$ of ELAH (ELAH control) Figure 6C. showed normal fibroblast morphology of MRC-5 cells in culture. Cells infected with 229E (virus control) showed 
marked CPE, as evident by rounding of infected cells and their lack of adherence to the surface of the chamber slide (Figure 6B). In contrast, MRC-5 cells pretreated with either $10 \mu \mathrm{g} / \mathrm{ml}$ (Figure 6D) or $1 \mu \mathrm{g} / \mathrm{ml}$ ELAH (Figure 6E) showed no significant CPE, as evident by the characteristic fibroblast cell morphology of the cell monolayers. These results suggest that pretreatment of MRC- 5 cells with either $10 \mu \mathrm{g} / \mathrm{ml}$ or 1 $\mu \mathrm{g} / \mathrm{ml}$ ELAH for 10 minutes prior to 2 hours of infection with 229E human coronavirus significantly inhibits replication and thus virus-induced cytopathic effects. Following bright field imaging, samples were fixed and processed for SEM imaging at the University of Wyoming per Methods and Materials.

High-resolution SEM. Images of control coronavirus 229E samples demonstrated virus attached to the surface of MRC- 5 cells (Figure 7a). When compared to MRC-5 cell only controls (Figure 7b.) or MRC-5 cells pretreated with $10 \mu \mathrm{g} / \mathrm{ml}$ ELAH (Figure 7c.) virus was significantly reduced from the surface. These data suggest that 10 minutes of pretreatment of MRC- 5 cells with ELAH $10 \mu \mathrm{g} / \mathrm{mL}$ prior to human coronavirus $229 \mathrm{E}$ challenge reduces viral entry and the cytopathic effects caused by the virus after 48 hours of incubation compared to controls.

\section{Discussion}

The primary mode of entry for severe respiratory syndrome coronavirus 2 is through the nasal area. While vaccines have been developed, other means, especially in the early stage of infections, are vitally important to arrest or reduce the transmission of virus through nasal passage. Effective antiviral therapies, especially in the early stage of infections, are vitally important to halt viral proliferation long enough for the immune system to respond to the virus, limit cellular damage inflicted by viral invasion and minimize genetic mutations caused by the high replication frequency of the virus, which might lead to therapeutic resistance.

COVID-19 infections have been reported worldwide. While effective treatments have been developed, the current emphasis is on using facial masks, applying hand sanitizers and social distancing, and masks alone cannot protect against transmission through aerosols and droplets. Therefore, effective antiseptics used in the nasopharynx or oral route are needed to reduce or prevent transmission. We used ethyl lauroly arginine hydrochloride monohydrate salt, hereafter referred to as ELAH, which is a special formulation for nasal application to prevent viral transmission. The antiviral and antivirucidal activities of arginine esters have been extensively studied by Yamasaki (Yamasaki, H. and others, 2011), and they concluded that the Cocoyl derivative of arginine inhibited virus growth of herpes virus (HSV-1) and poliovirus (PV-1) at $0.01 \%$ and identified its potential application as a therapeutic or preventative medicine against HSV superficial infections. We used lauric acid derivatives of arginine ester, which were not investigated by Yamasaki et al, since they are approved for use as food preservatives for meats and poultry. The main characteristic of this molecule is its unique surface activity. It has been shown that at very low concentrations, it reduced the surface free energy of protein-coated surfaces in oral and other mucosal surfaces from 25 dynes/cm to 15 dynes/cm. It has been shown that when the surface energy is reduced to 15 dynes/cm, no attachment of biofilms is observed on protein-coated mucosal surfaces, which prevents microbial films in vitro and in vivo (Glantz, PO 1969). Human clinical 
studies have confirmed these effects (Giersten and others, 2007, Gallob and other, 2015). Since ELAH is completely broken down in humans to body ingredients, arginine and lauric acid (Hawkins and other, 2009), it is an ideal ingredient for topical nasal applications.

We initially tested against SARS-CoV-2 and found that its effectiveness was as good as that of serum antibodies to the virus. Serum antibodies to the virus are known to block viruses from attaching to susceptible cell surfaces (Tandon, $R$ and others, 2020). This would indicate that the effect of ELAH could be blocking the susceptible surfaces on the cells.

The Syrian hamster model has been validated as a model replicating human SARS-CoV-2 infections. The study conducted by Shrivastava (Shrivastava 20121) showed the natural course of symptoms of viral COVID-19. The viral load increased from Days 1 to 7; however, after Day 7, it started to decrease. Additionally, COVID-19-infected patients normally show respiratory symptoms during the first 46 days after infection due to viral replication, inflammation and nasal mucosal damage and start stabilizing after 6 days. Our in vivo study in Syrian hamsters showed a similar pattern as determined by weight loss and clinical symptoms. Concomitants to clinical picture viral load as measured by genomic RNA and total RNA decreased in the treated group vs the control group.

The exact mechanism by which ELAH exerts its blocking effects on SAR-CoV-2 in vitro and in vivo cannot be determined by these studies. However, it is clear that effects could be perturbations in the virus and surface interactions with host cells. Similarity of the inhibition of pseudovirus to the serum antibody would indicate blocking effects at the surfaces. Ohatake, S. (Ohatake. S and others, 2010) proposed several mechanisms of the effects of arginine (breakdown product of ELAH). Three mechanisms were elucidated: structural changes in the viral spike proteins, virus aggregation and pore formation in the virus envelope. The most likely mechanism by which arginine inactivates the virus is most likely due to suppression of protein interactions with other molecules or surfaces. More importantly, they concluded that the effects of arginine were due to its weak interactions.

Our studies on the pretreatment of susceptible cell surfaces with noncytotoxic concentrations of ELAH and SEM analysis suggest that the blocking action against the virus can be explained by blocking or modifying the surface characteristics of the cell, resulting in the prevention of the virus from entering the cells.

\section{References}

Caldas, LA, Cameiro FA, Higa LM, Monteriro FL, Peixoto da silva, G, Decosta LJ, Durigon EL, Tanuri A, Desouza W.: Ultrastructural analysis of SARS-Cov-2 interactions with the host cell via high resolution electron microscopy: Nature scientific report (2020) 10:16099.

Gallob, J.T, Lynch.M, Charles.C, Ricci-Nattel, Mordas.C Gambogi, R,Revankar.R., Mutti.B, Labella, R (2015) Clinical periodontology 42,740-747: A randomized trial of ethyl lauroyl alginate-containing mouthwash in the control of gingivitis.

Page $12 / 18$ 
Gandhi, RT, Lynch, DelRio. C., (2020) Mild to moderate Covid-19. New England Journal of medicine.383(18):1757-66

Giersten, E, Guggenheim, B, Gemur, B (2007): Antiplaque effects of ethyl lauroyl arginase in situ: J. Dental research 86 (special issue) abstract 2299

Glantz, PO (1981) 'Adhesion in oral cavity'. In Fundamentals and application of surface interactions in the oral cavity (ed SA Leach) pp49-64. Information retrieval Ltd. London.

Hawkins, DR, Rocabeyera, X, Ruckman, S, Segret, R, Shaw, D (2009): Metabolism and pharmacokinetics of ethyl N(alpha)-L- lauroyl arginate hydrochloride in human volunteers: Food and chemical toxicology.47,2711-2715.

Li et al. (2021): In vitro and In vivo functions of SARS-Cov-2 infection-enhancing and neutralizing antibodies, Cell184(16):4203-4219

Koopmans, M. (2020) Novel coronavirus outbreak. What we know and what we don't. Cell: 180:1034-6

Ohtake, S. Arakawa,T and Koyama,A H(2010):Arginine as a synergistic virucidal agent. Macromolecules.15(3);1408-1424.

Shrivastava Vijay M, Maneby N. Clinical efficacy of an osmotic antiviral and anti-inflammatory polymeric nasal film to treat Covid-19 Early phase respiratory Symptoms. Open access Journal of clinical trials.2021 May18:13:11-20.

Tandon R. Mitra D, Sharma P, McCandlees MG, Stray SJ, Bates JT, Marshall GD: Effective screening of SARS-CoV-2 neutralizing antibodies in patient serum using lentivirus particles pseudo typed with SARSCoV-2 spike glycoprotein. (2020) Nature Scientific report: 10:19076

Tostanoski LH, Wegman F, Martinot AJ, Loos C, McMahan K, Mercado NB, Yu J, Chan CN Bondoc S, Starke CE and thirty-three others(2020). Nature Medicine Letters. https://doi.org/10.1038/s41591-020107

Whitt,MA(2010): Generation of VSV Pseudotypes Recombinant delta-G-VSV for studies of virus entry, identification of inhibitors, and immune responses to vaccines:J. Virol methods:169(2):365-74

Wofel,VM,Guggemos,W.,Scilmair,M,Zange,S.MullerMA,Neimeyer,D.JonesTC,VollarP., Rothe, C. (2020)" virological Assessment of Hospitalized Patients with Covid-2019". Nature 581-(7809)465-69

Yamasaki, Tsujimoto K, Ikeda K, Suzuki Y, Arakawa T and Koyama AH (2011): Antiviral and Virucidal activities of N (alpha)-Cocoyl-L- Arginine ethyl ester: Advances in Virology: article ID 572868, pages 6.

\section{Declarations}


Conflict of interest: Dr. Thacore is a consultant in virology for Salvacion USA Inc. with no financial interest in the company; Drs. Gaffar and Yun are part of Salvacion USA Inc. which has interest in commercializing the spray; Drs. Chenine (IBT), Ferrari, Pal and Wattay (Bioqual) and Peterson (Perfectus) are independent contractors conducting the studies described in the communication.

Author contributions: Drs. HT and AG wrote and edited the main manuscript text and supervised the experiments; Dr. SY developed the formulation. Drs. AC, MF, RP, LW and MP conducted respective studies.

\section{Figures}

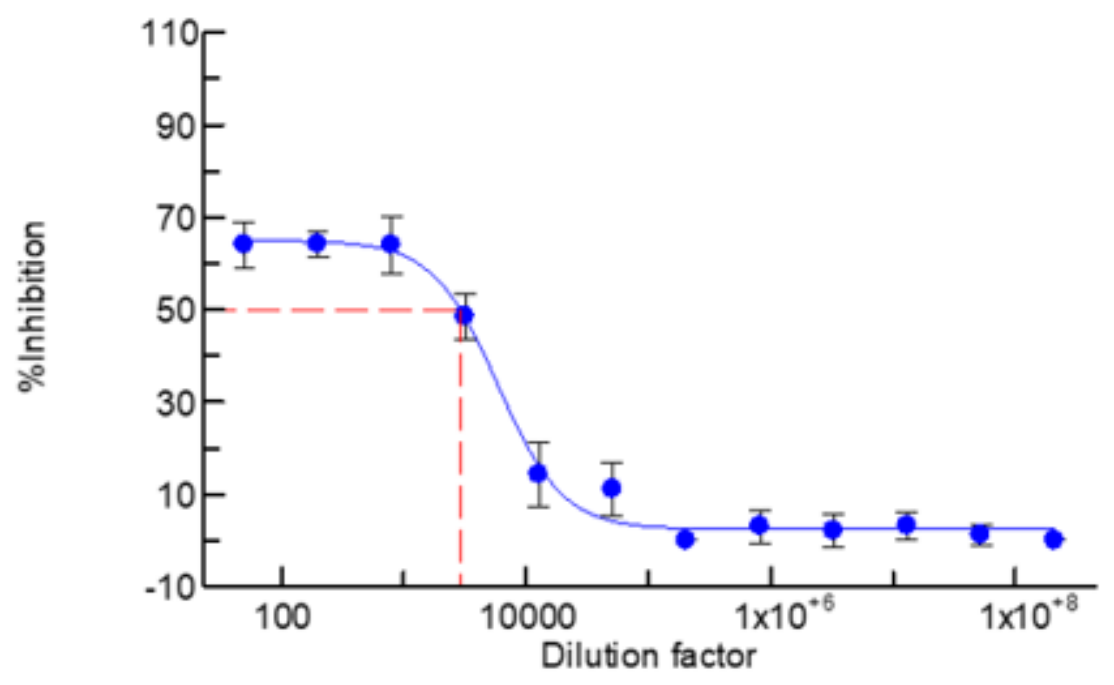

\section{Figure 1}

Inhibition of rVSV-SARS-2S replication in Vero cells by pretreatment with neutralizing antibody serum for 1 hour at $37^{\circ} \mathrm{C}$.

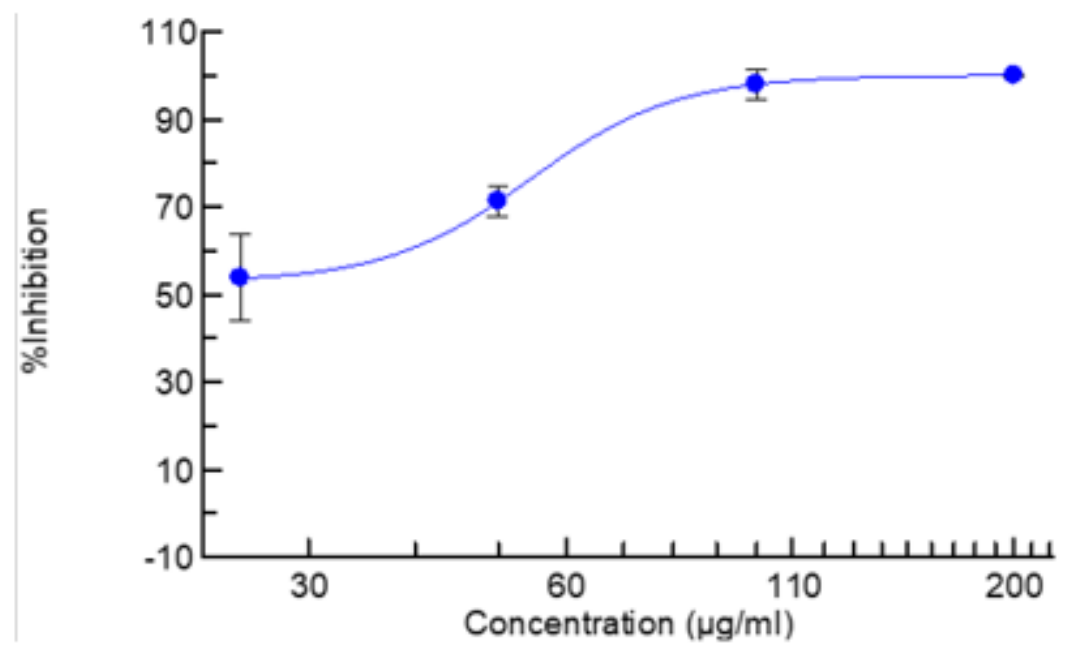




\section{Figure 2}

Inhibitory effect of ELAH on the replication of rVSV-SARS-CoV-2S in Vero cells.
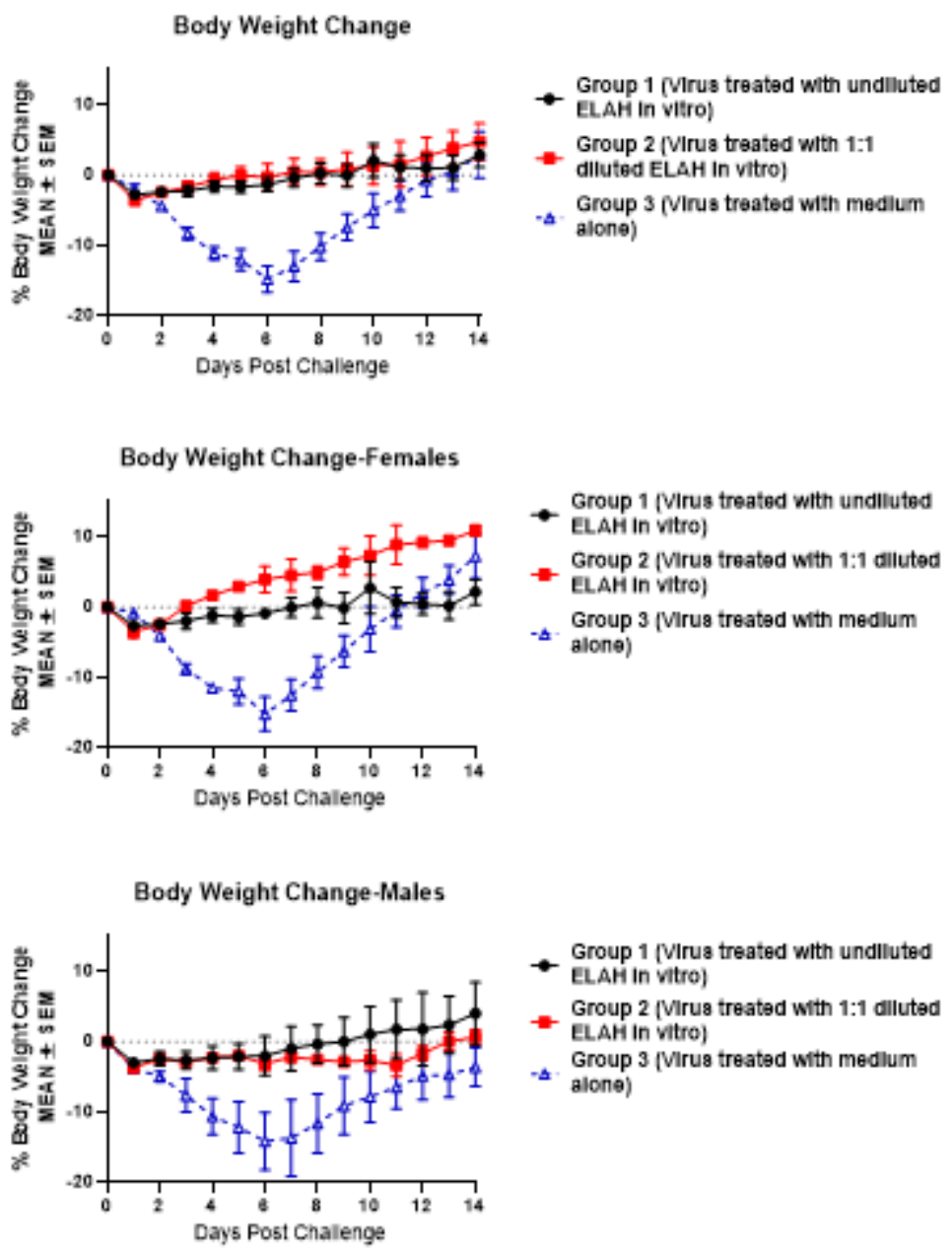

\section{Figure 3}

3A. Body weight changes observed in all animals throughout the course of the study. The body weights were measured daily post challenge until day 14 . The data represent the mean percent change in body weight for each group from the starting body weight observed on day 0 post challenge. The error bars for the group means represent the standard error of the mean (SEM). 3B. Body weight changes were observed in all female animals throughout the course of the study, and body weights were measured daily post challenge until necropsy on day 4 . The data represent the mean percent change in body weight for each group from the starting body weight observed on day 0 post challenge. The error bars for the group means represent the standard error of the mean (SEM). 3C. Body weight changes observed in all male animals throughout the course of the study. The body weights were measured daily post challenge until necropsy on day 4 . The data represent the mean percent change in body weight for each group from the starting body weight observed on day 0 post challenge. The error bars for the group means represent the standard error of the mean (SEM). 


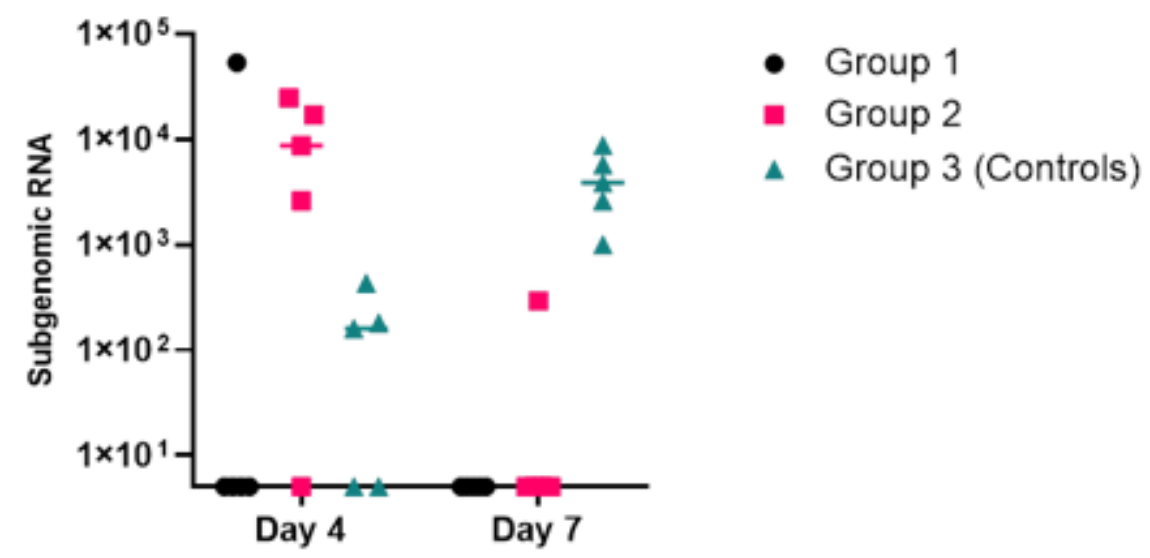

Figure 4

Number of subgenomic RNA copies in control animals (Group 3) and animals treated with $50 \mu \mathrm{g} / \mathrm{ml}$ ELAH (Group 1) and $25 \mu \mathrm{g} / \mathrm{ml}$ ELAH (Group 2).

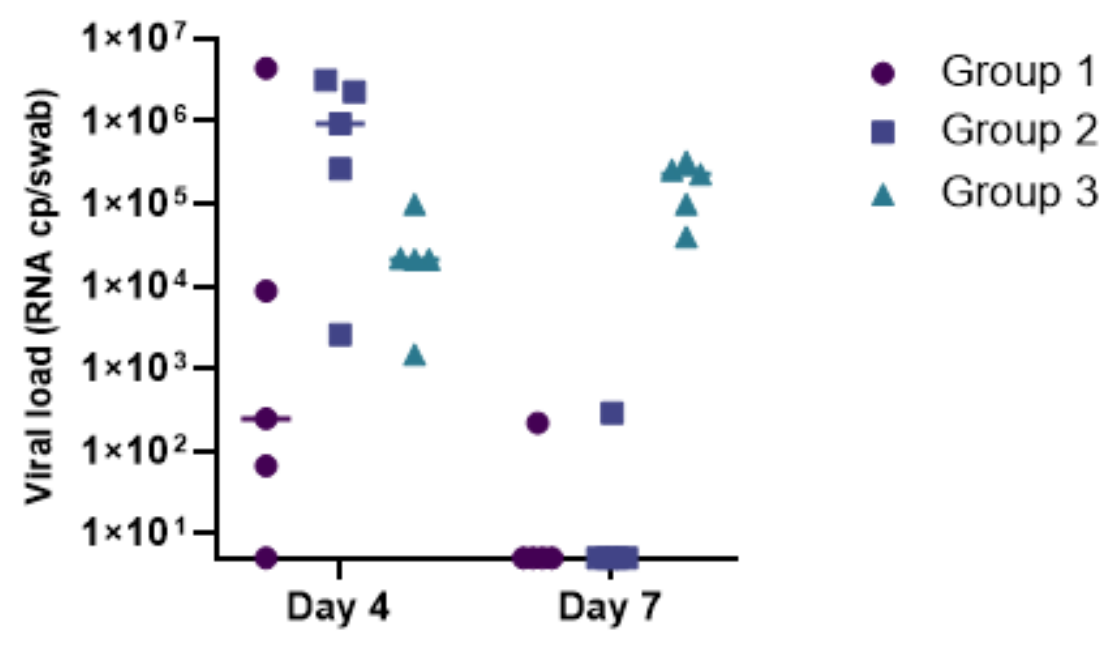

Figure 5

Viral RNA load results are represented as geometric mean and geometric standard deviation. 


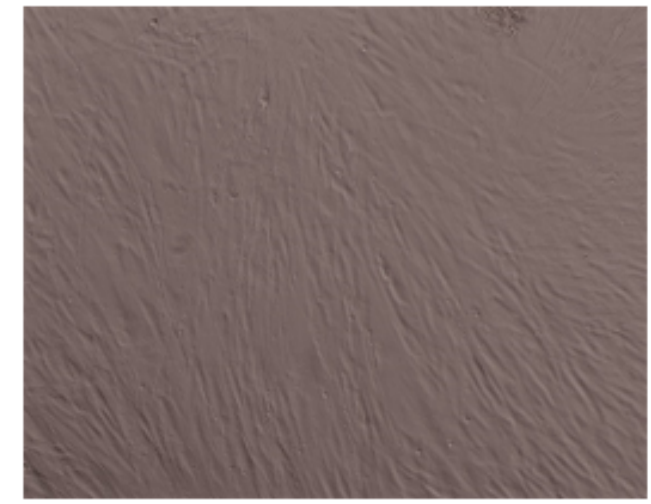

A

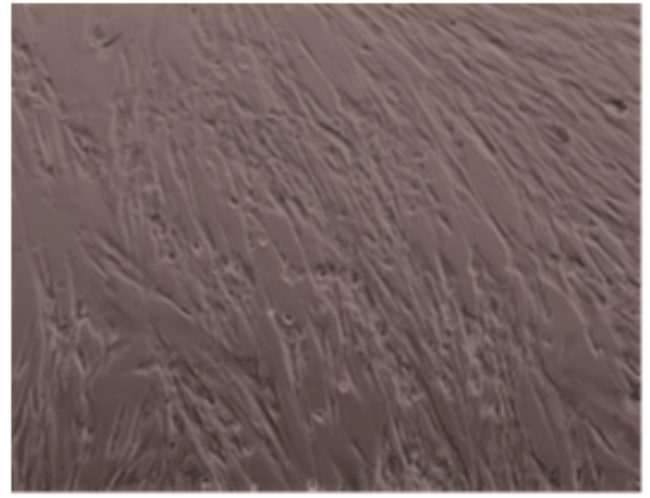

B
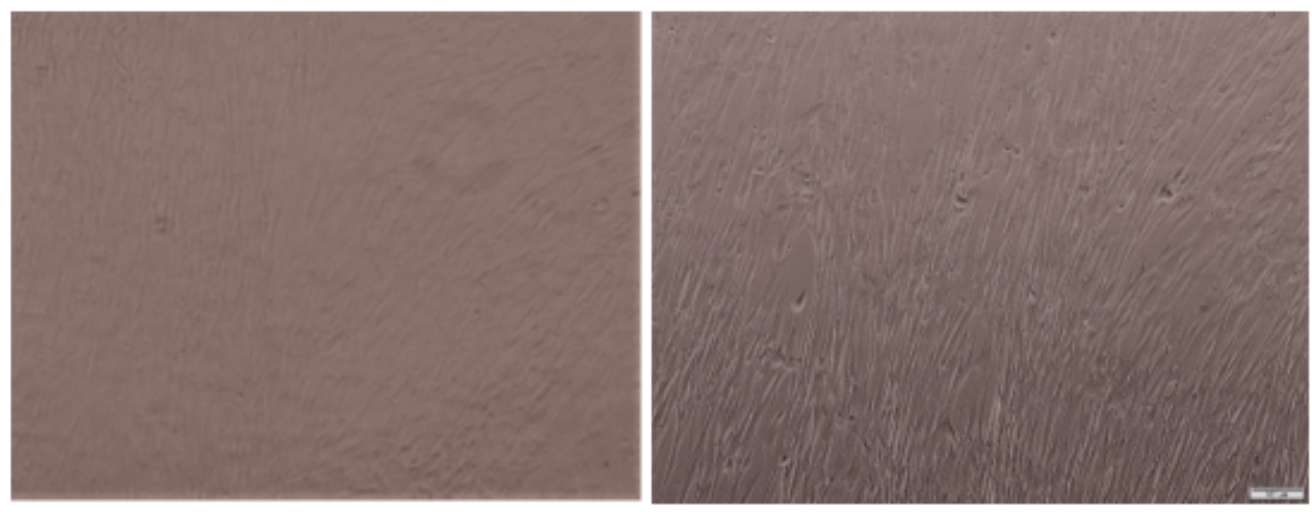

$\mathrm{C}$

D

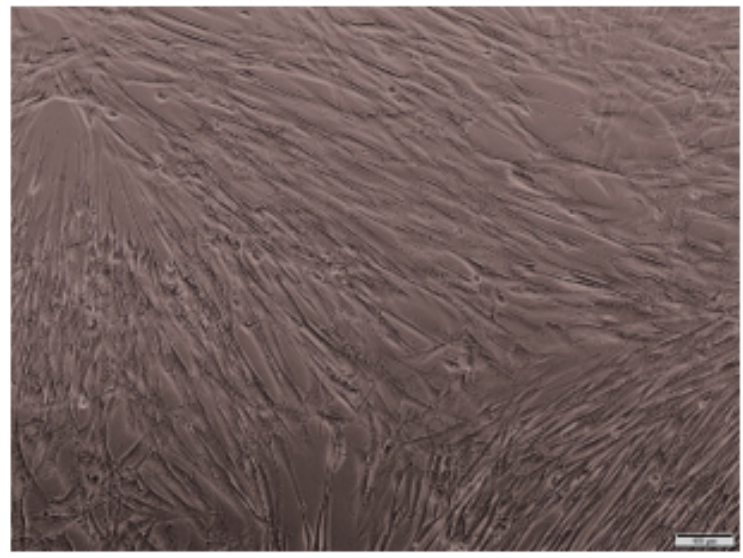

$\mathrm{E}$

\section{Figure 6}

Inhibition of cytopathic effect by human coronavirus 229E in MRC-5 cells pretreated with ELAH: A. MRC-5 cells with medium only (cell control); B. MRC-5 cells infected with human coronavirus 229E; C. MRC-5 cells pretreated with $10 \mu \mathrm{g} / \mathrm{ml}$ ELAH for 10 minutes (ELAH control); D. MRC- 5 cells pretreated with 10 $\mu \mathrm{g} / \mathrm{ml}$ ELAH for 10 minutes prior to minutes prior to infection with 229E; EMRC-5 cells pretreated with 1 $\mu \mathrm{g} / \mathrm{ml}$ EALH for 10 minutes prior to infection with 229E. Images obtained at x63 magnification. 

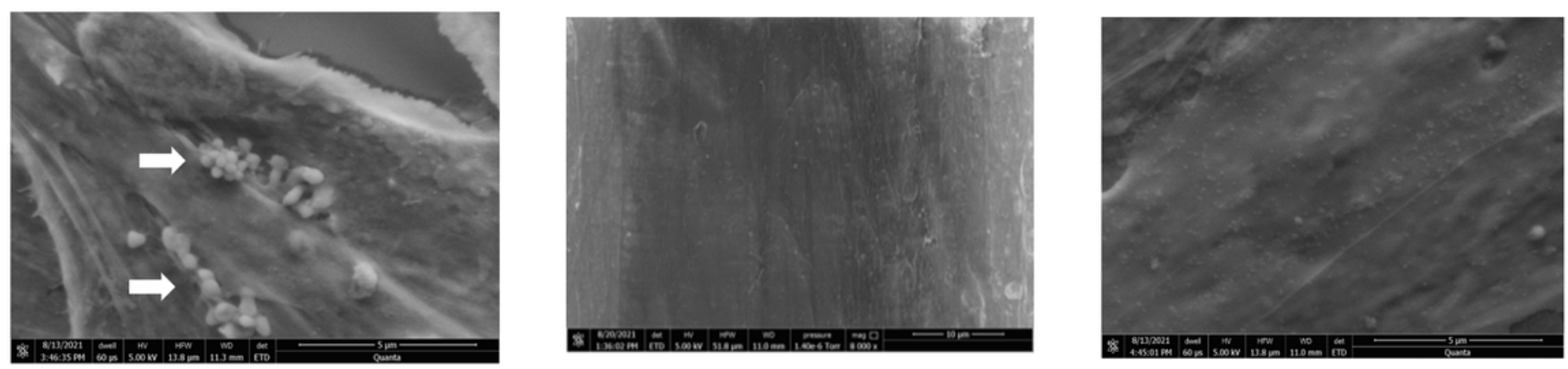

Figure 7

7a: Control. High-resolution SEM of MRC-5 cells after two hours of exposure to human coronavirus 229E (10E-3 dilution) and then rinsed to remove virus and 48 hours of incubation. Arrows showing viral particles on the cells, $5 \mu \mathrm{m}$ magnification. 7b: Control. High-resolution SEM of MRC- 5 cells only after 48 hours of incubation. Image $10 \mu \mathrm{m}$ magnification. 7c: Control. High-resolution SEM of MRC-5 cells after 10 minutes of exposure to $10 \mu \mathrm{g} / \mathrm{ml}$ ELAH (nontoxic concentration) followed by unbound active ELAH removal and 2 hours of exposure to coronavirus $229 \mathrm{E}$ (10E-3 dilution) was performed. Then, the cells were rinsed to remove virus and incubated for 48 hours. Image $5 \mu \mathrm{m}$ magnification. 